Mikuláš Zvánovec

Der nationale Schulkampf in Böhmen 



\section{Mikuláš Zvánovec}

Der nationale

Schulkampf in

Böhmen

Schulvereine als Akteure der nationalen

Differenzierung (1880-1918) 
Das vorliegende Buch wurde durch den Forschungsverbund „Grenze/ $\mathrm{n}$ in nationalen und transnationalen Erinnerungskulturen zwischen Tschechien und Bayern“ gefördert, der durch die Bayerisch-Tschechische Hochschulagentur getragen wurde.

\section{Bayerisch-Tschechische Hochschulagentur}

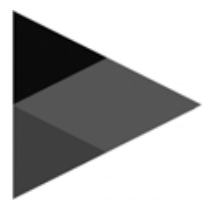

\section{Česko-bavorská vysokoškolská agentura}

ISBN 978-3-11-072334-2

e-ISBN (PDF) 978-3-11-072339-7

e-ISBN (EPUB) 978-3-11-072345-8

\section{Library of Congress Control Number: 2021932011}

\section{Bibliografische Information der Deutschen Nationalbibliothek}

Die Deutsche Nationalbibliothek verzeichnet diese Publikation in der Deutschen Nationalbibliografie; detaillierte bibliografische Daten sind im Internet über http://dnb.dnb.de abrufbar.

\section{(C) 2021 Walter de Gruyter GmbH, Berlin/Boston}

Umschlagabbildung: Ansichtskarte des tschechischen Schulvereins Ústřední matice školská, Privatarchiv des Verfassers

Satz: bsix information exchange $\mathrm{GmbH}$, Braunschweig Druck und Bindung: CPI books $\mathrm{GmbH}$, Leck

www.degruyter.com 
Für Veronika, Max und Alex 
